\title{
Web Usage Mining Menggunakan Algoritma Clastering K-Mean
}

\author{
Mira Orisa \\ Teknik Informatika S1 \\ (Fakultas Teknologi Industri) \\ ITN Malang \\ (ITN Malang) \\ Malang, Indonesia \\ mir4orisa@gmail.com
}

\author{
Michael Ardita \\ Teknik Informatika S1 \\ (fakultas teknologi Industri) \\ ITN Malang \\ (ITN Malang) \\ Malang, Indonesia \\ michael.ardita@lecturer.itn.ac.id
}

\begin{abstract}
Abstrak - Big data merupakan sumber informasi yang besar. Sebelum menjadi informasi tentu big data tersebut harus di ektrasi terlebih dahulu untuk mendapatkan pengetahuan. Disiplin ilmu yang mempelajari pengektraksian big data menjadi pengetahuan disebut data mining. Banyak teknik pengolahan data dalam data mining, salah satunya adalah teknik clustering. Teknik clustering dapat digunakan untuk mengektraksi big data menjadi pengetahuan. Pengetahuan yang dihasilkan pada teknik clustering berupa cluster-cluster. Teknik clustering dapat mengclusterkan tingkah laku dari pengguna suatu website. Pada suatu log server web mengandung banyak sekali data yang dapat diambil pengetahuannya. Ada beberapa tahap untuk mendapatkan pengetahuan. Tahap pertama aka dilakukan preprocessing data yaitu untuk membersihkan data dari atribut-atribut data yang tidak diperlukan. Pada tahap pattern discovery dilakukan pengektraksian dataset dengan algoritma K-means clustering. Pada tahap pattern analysis dilakukan analisis cluster-cluster yang dihasilkan oleh algoritma $K$-means clustering. Hasil yan diperoleh bergantung pada nilai centroid awal.Pada skenario 1 menghasilkan web 7,14,18,19 termasuk cluster 1. web 1,3,5,10 termasuk cluster 2. Dan web $\mathbf{2 , 4 , 6 , 8 , 9 , 1 1 , 1 2 , 1 3 , 1 5 , 1 6 , 1 7 , d a n ~} 20$ termasuk cluster 3. Hasil pada skenario 2 yaitu web 1,3,5,7,10,14,18 dan 19 termasuk cluster 1 . Hanya web 2 yang temasuk cluster 2.sedangkan web $4,6,8,9,11,12,13,15,16,17$, dan 20 termasuk cluster 3.
\end{abstract}

Keywords-komponen; big data, clustering, algoritma $k$ means,

\section{PENDAHULUAN}

Pengolahan data dalam jumlah besar sering dikaji dalam disiplin ilmu data scientist. Pengolahan data yang tak terstruktur dalam jumlah yang besar tanpa bantuan algoritma tertentu sungguh merupakan pekerjaan yang sangat sulit dan memakan waktu yang lama. Dalam bidang ilmu data scientist, data-data tak terstruktur tersebut dapat diolah dengan bantuan machine learning. machine learning akan membuat data-data dapat diolah oleh komputer sehingga manusia mendapatkan informasi tertentu. Informasi ini seringkali digunakan untuk menentukan arah kebijakan suatu perusahaan.

Usaha untuk mendapatkan informasi dengan pola tertentu dari sebuah data yang berukuran besar disebut juga data mining. Data mining atau pengalian data merupakan bagian proses dari ilmu data scientist. Ada banyak penggunaan machine learning untuk mendapatkan informasi dari data yang diolah tersebut. Seperti penggunaan machine learning naïve bayes untuk mendapatkan informasi mengenai kalsifikasi kelayakan dari data-data program raskin[1]. Penggunaan machine learning algoritma genetika untuk mendapatkan informasi mengenai keragaman populasi[2]. Penggunaan Machine learning $K$-means untuk pengolahan data mahasiswa untuk pengambilan keputusan tertentu seperti keputusan penentapan kebijakan untuk uang kuliah[3]. Pengunaan machine learning $K$-means juga diterapkan untuk pengelompokkan data-data obat-obatan sebagai bahan pengambil keputusan dalam analisis dan pengendalian obatobatan[4]. Kemudian untuk analisis data kerusakan tanaman cabe. Jadi dengan menggunakan machine learning K-means dapat menggali informasi untuk menentukan pengelompokan penyebab kerusakan pada tanaman tersebut[5]. Pengunaan machine learning $K$-means juga diterapkan untuk menentukan strategi penjualan variasi mobil[6].Penggunaan machine learning K-means untuk menggali informasi mengenai pengelompokkan penumpang bandara[7]. Penggunaan machine learning fuzzy C-means Clustering untuk pengelompokan kejadian gempa bumi[8].Penggunaan $K$ means Clustering untuk menganalisis bisnis di perusahaan asuransi[9].

Berdasarkan penelitian pada 5 tahun terakhir bahwa machine learning $K$-means sudah terbukti mampu memberikan pengetahuan tertentu berdasarkan kasus yang diteliti oleh masing-masing peneliti. Oleh sebab itu maka pada penelitian ini akan dikembangkan machine learning $K$-means pada pengolahan data log server web untuk menggali pengetahuan tentang cluster-cluster pengguna web.

\section{DATA MINING}

Data mining merupakan disiplin ilmu yang mempelajari cara menganalisis data dalam ukuran yang besar yang tersimpan di sebuah database(knowledge discovery in database). Atau disebut penambangan pengetahuan dari data, ekstraksi pengetahuan, analisis data / pola, data arkeologi, dan pengerukan data. Ada beberapa langkah dalam proses penemuan pengetahuan yang ditunjukkan seperti Gambar 1.Dalam proses penemuan pengetahuan lagkah demi langkah yang harus dijalankan yaitu[10]:

1. Pembersihan data (data cleaning)

2. Intergrasi data

3. Menyeleksi data

4. Tramsformasi data

5. Data mining atau proses mengektraksi big data dengan algoritma tertentu

6. Evalusi pola

7. Presentasi pengetahuan

Sumber data pada data mining dapat berupa database, data gudang, Web, repositori informasi lainnya[10]. 


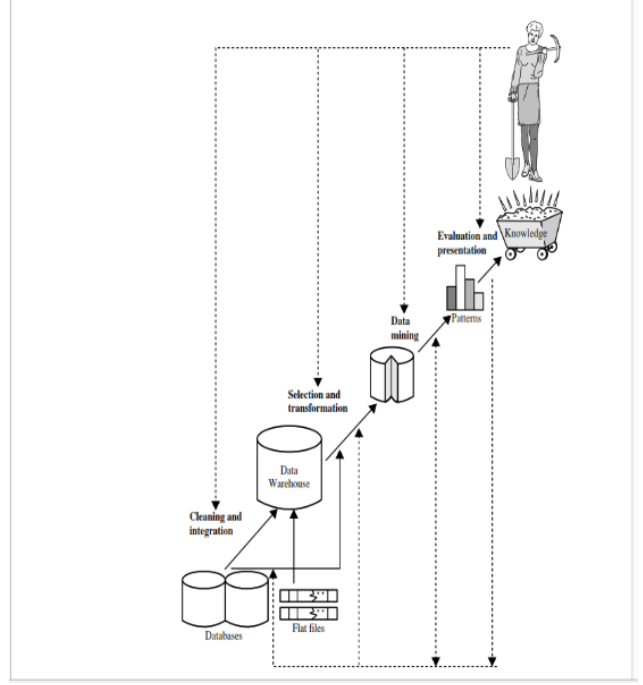

Fig. 1. Tahapan proses Penambangan pengetahuan dalam data mining(morgan ...page 7)

\section{WEB USAGE MINING}

Web usage mining merupakan teknik untuk menemukan pola aktifitas dari log pengguna web. Adapun tujuan untuk menangkap dan memodelkan pola perilaku dan profil pengguna yang berinteraksi dengan situs web. Dalam proses web usage mining terdapat beberapa tahap seperti:[11]

1. Pengumpulan data dan pra-pemprosesan data

2. Penemuan pola (Pattern discovery)

3. Analisis pola (Pattern analysis)

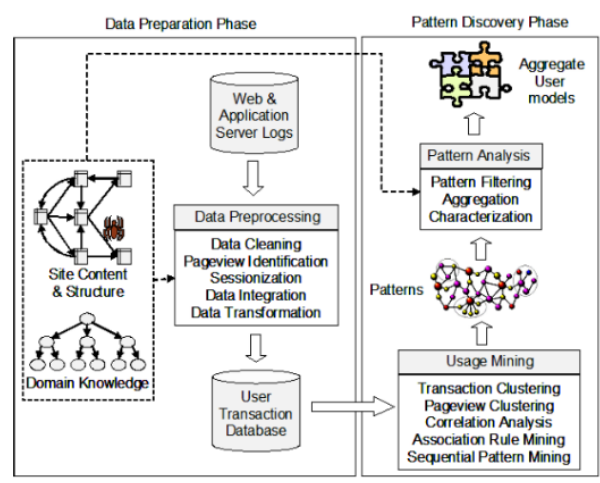

Fig. 2. Tahapan proses pada web usage mining (bing liu.2011.web data mining.second edition.springer.page 528)[11]

\section{ALGORITMA CLASTERING K-MEANS}

Clustering adalah teknik mengelompokkan atau membagi datake dalam cluster-cluster dimana objek dalam suatu cluster memiliki kemiripan yang tinggi. Tetapi memiliki perbedaan yang tinggi pula dengan objek pada cluster lainnya. Data yang dikelompokkan adalah data-data yang memiliki atribut numerik. Ada data yang memiliki label dan ada juga data yang tidak memiliki label. Pada clustering akan dicari terlebih dahulu adalah centroid awal atau titip pusat dari kelompok data. Ada beberapa kelompok metode clustering menurut para ahli yaitu[10]:

1. Metode berbasis partisi (partitioning methods)

2. Metode berbasis hirarki (hierarchical methods)

3. Metode berbasis kepadatan (density-based methods)

\section{Metode berbasis kisi (grid-based methods)}

Algoritma K-means adalah algoritma yang termasuk kedalam metode partisi (partitioning methods). Metode ini mempartisi data ke dalam kelompok-kelompok atau kluster. Metode ini bekerja dengan menentukan nilai centroid tiap kelompok/cluster. Centroid adalah titik pusat kluster. Algoritma $K$-means meminimalkan sum of squared error (SSE) antar objek-objek data dengan sejumlah k centroid. Ada beberapa langkah kerja dari algoritma K-means yaitu diperlihatkan oleh Fiq 1 berikut[10]. Fig. 3. Gambar ilustrasi pseudo code algoritma K-means
clustering(morgan)

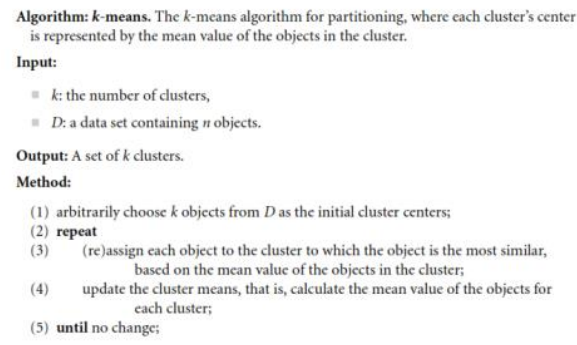

Berdasarkan fiq 3 diatas bahwa algoritma $K$-means akan memilih secara acak untuk centroid awal(k). kemudian algoritma ini akan melihat objek yang bukan termasuk centroid awal akan dimasukkan kedalam kluster terdekat. Penentuan kluster terdekatnya berdasarkan ukuran jarak tertentu. Setelah itu centroid akan diperbaharui berdasarkan nilai rata-rata objek-objek yang ada di masing-masing kluster. Dua langkah tersebut yaitu langkah mengelompokkan objek kedalam kluster berdasarkan kedekatan ukuran jaraknya dan memperbaharui nilai centroid akan selalu diulang hingga semua centroid yang dihasilkan tidak berubah lagi atau bernilai tetap atau bernilai sama dengan centroid sebelumnya. Algoritma K-means akan menghasilkan sebuah output berdasarkan nilai centroid awalnya,dimana kita ketahui bahwa nilai centroid awal dipilih secara acak. Oleh sebab itu perlu melakukan beberapa percobaan pengambilan nilai centroid awalnya untuk mendapatkan hasil terbaik.[10]

\section{EUCLIDEAN DISTANCE}

Euclidean distance merupakan salah satu formula yang biasa digunakan untuk menghitung jarak antara dua objek yang memiliki atribut numerik selain formula manhattan distance, minkowski distance, dan supremum distance. Formula Euclidean distance [9]:

$$
d(\mathrm{i}, \mathrm{j})=\sqrt{\left(x_{i 1}-x_{j 1}\right)^{2}}+\left(x_{i 2}-x_{j 2}\right)^{2}+\cdots . .+\left(x_{i p}-x_{j p}\right)^{2}
$$

Dimana i dan j merupakan objek data memiliki $\mathrm{p}$ atribut bernilai numerik

$$
\begin{aligned}
& \mathrm{i}=\left(\left(x_{i 1}, x_{i 2}, \ldots . x_{i p}\right)^{2}\right) \\
& \mathrm{j}=\left(\left(x_{j 1}, x_{j 2}, \ldots . . x_{j p}\right)^{2}\right)
\end{aligned}
$$

\section{A. Pra-pemprosesan}

\section{METODE PENELITIAN}

Tahap pra-pemprosesan adalah tahap melakukan pembersihan data,intergrasi data, menyeleksi data dan melkukan transformasi data sehingga hanya data yang diperlukan dan relevan saja yang diolah. Data dari Table I 
akan di ekstraksi sehingga didapatkanlah beberapa atribut seperti berikut.

TABLE I. DATASET

\begin{tabular}{|r|r|r|}
\hline akses gam akses text akses audio/video & \\
\hline 156 & 150 & 44 \\
\hline 46 & 104 & 100 \\
\hline 179 & 169 & 102 \\
\hline 75 & 50 & 50 \\
\hline 190 & 100 & 75 \\
\hline 125 & 80 & 50 \\
\hline 301 & 105 & 50 \\
\hline 99 & 70 & 30 \\
\hline 107 & 71 & 56 \\
\hline 175 & 100 & 49 \\
\hline 90 & 80 & 19 \\
\hline 75 & 75 & 51 \\
\hline 100 & 65 & 37 \\
\hline 189 & 56 & 22 \\
\hline 80 & 50 & 37 \\
\hline 87 & 60 & 40 \\
\hline 125 & 48 & 36 \\
\hline 203 & 75 & 31 \\
\hline 275 & 75 & 50 \\
\hline 103 & 80 & 24 \\
\hline
\end{tabular}

(peneliti.2021)

B. Pattern Discovery.

Untuk mengelompokkan data-data berdasarkan waktu akses dan kategori akses maka digunakan algoritma Kmean.

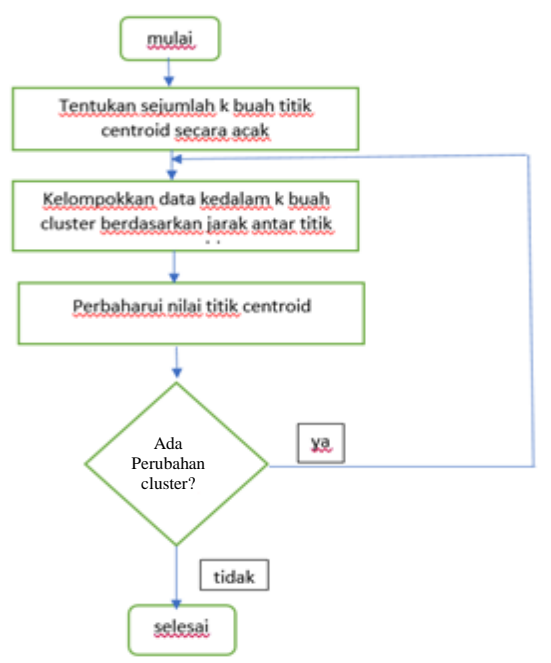

Fig. 4. Flowchar kerja algoritma K-means (peneliti,2021)

Alur kerja dari algoritma $K$-means adalah menentukan terlebih dahulu jumlah $\mathrm{k}$ buah titik centroid. Penentuan ini dilakukan secara acak. Algoritma $K$-means mengelompokkan data-data ke dalam sejumlah $\mathrm{k}$ buah yang sudah ditentukan sebelumnya berdasarkan nilai jarak terdekat dari dua buah titik centroid. Algoritma $K$-means akan mengulang langkah tersebut hingga titik centroid tidak lagi mengalami perubahan.

\section{Pattern Analisis}

Setelah pola ditemukan maka akan dilakukan analisis terhadap pola tersebut untuk menentukan pola-pola yang tidak relevan.

\section{HASIL DAN PEMBAHASAN}

Data yang diolah menggunakan Algoritma K-means menghasilkan pengetahuan berupa cluster-cluster yaitu cluster cluster pengakses gambar/image, cluster pengakses teks, dan cluster pengakses audio/video. Hasil dari algoritma $K$-means bergantung pada nilai centroid awal.

\section{A. Hasil pengujian skenario 1}

Nilai centroid awal pada skenaro 1 untuk ke tiga cluster ditunjukkan oleh Tabel 2 . Nilai centroid pada cluster 1 akses gambar sebesar 275, sedangkan nilai centroid pada cluster 2 sebesar 75, dan nilai centroid pada cluster 3 sebesar 50. Nilai centroid pada cluster 1 akses teks sebesar 179, sedangkan nilai centroid pada cluster 2 sebesar 169, dan nilai centroid pada cluster 3 sebesar 102. Nilai centroid pada cluster 1 akses video sebesar 46, sedangkan nilai centroid pada cluster 2 sebesar 104, dan nilai centroid pada cluster 3 sebesar 100

\begin{tabular}{|c|c|c|c|}
\hline TABLE II. & \multicolumn{2}{|c|}{ TABEL CENTROID AWAL SKENARIO 1} & KENARIO 1 \\
\hline atribut & c1 & c2 & c3 \\
\hline akses gambar & 275 & 75 & 50 \\
\hline akses teks & 179 & 169 & 102 \\
\hline akses video & 46 & 104 & 100 \\
\hline
\end{tabular}

(peneliti.2021)

TABLE III. TABEL CENTROID PADA ITERASI 1 SKENARIO 1

\begin{tabular}{|l|r|r|r|}
\hline atribut & c1 & c3 \\
\hline akses gambar & 242 & 77,75 & 38,25 \\
\hline akses teks & 175 & 129,75 & 67,5 \\
\hline akses video & 92,66666667 & 69,41666667 & 44,16666667 \\
\hline (peneliti.2021) & & &
\end{tabular}

Hanya diperlukan satu kali iterasi karena pembagian cluster awal dengan pembagian cluster pada iterasi 1 sudah sama tidak ada perubahan.Dan Nilai centroid pada iterasi 1 ditunjukkan oleh Tabel 3. Nilai centroid pada cluster 1 akses gambar sebesar 242, sedangkan nilai centroid pada cluster 2 sebesar 77,75, dan nilai centroid pada cluster 3 sebesar 38,25. Nilai centroid pada cluster 1 akses teks sebesar 175 , sedangkan nilai centroid pada cluster 2 sebesar 129,75, dan nilai centroid pada cluster 3 sebesar 67,5. Nilai centroid pada cluster 1 akses video sebesar 92,666, sedangkan nilai centroid pada cluster 2 sebesar 69,416, dan nilai centroid pada cluster 3 sebesar 44,166. Hasil implementasi algoritma K-means clustering ditunjukkan pada Fig 5. Pengetahuan yang dihasilkan oleh aplikasi berbasis android tersebut yaitu web $7,14,18,19$ termasuk ke dalam cluster Gambar. Sedangkan web 1,3,5,10 termasuk ke dalam cluster Teks.Dan selebihnya termasuk kedalam cluster video yaitu $2,4,6,8,9,11,12,13,15,16,17$,dan 20 . 

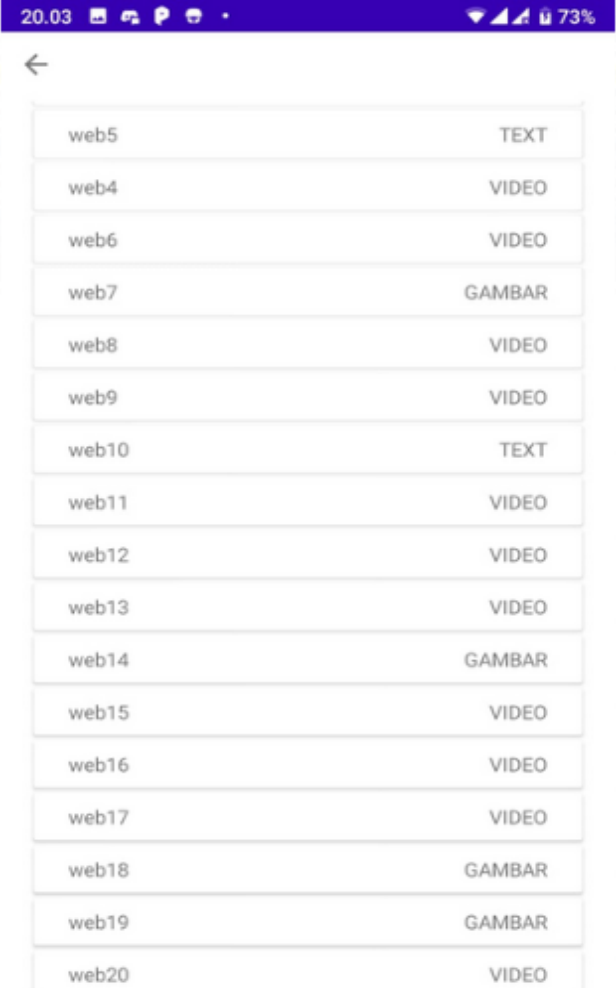

Fig. 5. Hasil implementasi algoritma $K$-means pada OS android TABLE IV. TABEL PENGETAHUAN

\begin{tabular}{|c|c|c|c|c|c|c|c|}
\hline nama website & Gambar & Video & D1 & D2 & D3 & MIN & CLUSTER \\
\hline website 1 & 156 & 150 & 44 & 112,4683289 & 36,37736247 & 102,4929876 & $36,37736247 \mathrm{C2}$ \\
\hline website 2 & 46 & 104 & 100 & 207,1669013 & 135,5002306 & 80,56764756 & 80,56764756 C3 \\
\hline website 3 & 179 & 169 & 102 & 127,9047497 & 52,41004198 & 143,9269925 & $52,41004198 \mathrm{C} 2$ \\
\hline website 4 & 75 & 50 & 50 & 169,6971567 & 129,0980732 & 26,89137098 & $26,89137098 \mathrm{C} 3$ \\
\hline website 5 & 190 & 100 & 75 & 67,45090807 & 34,15131769 & 106,5824212 & $34,15131769 \mathrm{C2}$ \\
\hline website 6 & 125 & 80 & 50 & 117,6100548 & 72,67263928 & 34,51780941 & 34,51780941 C3 \\
\hline website 7 & 301 & 105 & 50 & 66,04259989 & 129,5948012 & 211,4307905 & $66,04259989 \mathrm{C1}$ \\
\hline website 8 & 99 & 70 & 30 & 143,44729 & 103,693358 & 15,52887096 & $15,52887096 \mathrm{C} 3$ \\
\hline website 9 & 107 & 71 & 56 & 136,3291055 & 90,59697843 & 18,65419971 & 18,65419971 C3 \\
\hline website 10 & 175 & 100 & 49 & 71,41165871 & 35,03302014 & 87,96294201 & 35,03302014 C2 \\
\hline website 11 & 90 & 80 & 19 & 153,2306268 & 109,7830246 & 27,43135372 & 27,43135372 C3 \\
\hline website 12 & 75 & 75 & 51 & 167,5085819 & 115,1946722 & 19,74789018 & 19,74789018 C3 \\
\hline website 13 & 100 & 65 & 37 & 142,5767337 & 103,6716572 & 11,16448984 & 11,16448984 C3 \\
\hline website 14 & 189 & 56 & 22 & 59,549349228 & 87,779900443 & 99,75710083 & $59,54934928 \mathrm{C} 1$ \\
\hline website 15 & 80 & 50 & 37 & 164,3643057 & 127,7314076 & 24,26545899 & $24,26545899 \mathrm{C} 3$ \\
\hline website 16 & 87 & 60 & 40 & 156,0228349 & 115,6084448 & 11,75354556 & 11,75354556 C 3 \\
\hline website 17 & 125 & 48 & 36 & 120,7440475 & 100,872754 & 39,63347701 & 39,63347701 C3 \\
\hline website 18 & 203 & 75 & 31 & 39,76336253 & 71,51092574 & 111,2563669 & $39,76336253 \mathrm{Cl}$ \\
\hline website 19 & 275 & 75 & 50 & 35,13723097 & 115,342154 & 182,512043 & $35,13723097 \mathrm{C1}$ \\
\hline website 20 & 103 & 80 & 24 & 139,7466458 & 97,73081653 & 25,0095815 & 25,0095815 C3 \\
\hline
\end{tabular}

Hasil perhitungan ditunjukkan pada Tabel 4. Pada tabel tersebut ditunjukkan nilai D1 merupakan jarak website dengan nilai centroid 1. D2 merupakan jarak website dengan nilai centroid 2. D3 adalah jarak website dengan nilai centroid 3. Algoritma K-means mengelempokkan web berdasarkan jarak terdekat dengan titik centroid. Website 1 termasuk ke dalam cluster 2 yaitu cluster teks berdasarkan nilai minimumnya adalah di D2 sebesar 36,3777 seperti terlihat pada Tabel 4.Begitu juga website 2 termasuk ke dalam cluster 3 berdasarkan nilai minimumnya berada di D3 sebesar 80,567. Website 3 termasuk ke dalam cluster 2 juga sama seperti website 1 karena website 3 memiliki nilai minimum yang berada di D2 sebesar 52,410. Website 4 termasuk ke dalam cluster 3 yaitu cluster video karena memiliki nilai minimum di D3 sebesar 26,891. Website 5 termasuk ke dalam cluster 2 yaitu cluster teks karena memiliki nilai minimum di D2 sebesar 34,151. Website 6 termasuk ke dalam cluster 3 yaitu cluster video karena memiliki nilai minimum di D3 sebesar 34,517. Website 7 termasuk ke dalam cluster 1 yaitu cluster gambar karena memiliki nilai minimum di D1 sebesar 66,042. Website 8 termasuk ke dalam cluster 3 yaitu cluster video karena memiliki nilai minimum di D3 sebesar 15,528. Website 9 termasuk ke dalam cluster 3 juga yaitu cluster video karena memiliki nilai minimum di D3 sebesar 18,654. Website 10 termasuk ke dalam cluster 2 yaitu cluster teks karena memiliki nilai minimum di D2 sebesar 35,033. Website 11 termasuk ke dalam cluster 3 yaitu cluster video karena memiliki nilai minimum di D3 sebesar 27,431. Website 12 termasuk ke dalam cluster 3 juga yaitu cluster video karena memiliki nilai minimum di D3 sebesar 19,747. Website 13 termasuk ke dalam cluster 3 yaitu cluster video karena memiliki nilai minimum di D3 sebesar 11,164. Website 14 termasuk ke dalam cluster 1 yaitu cluster gambar karena memiliki nilai minimum di D1 sebesar 54,549. Website 15 termasuk ke dalam cluster 3 yaitu cluster video karena memiliki nilai minimum di D3 sebesar 24,265. Website 16 termasuk ke dalam cluster 3 juga yaitu cluster video karena memiliki nilai minimum di D3 sebesar 11,753. Website 17 termasuk ke dalam cluster 3 yaitu cluster video karena memiliki nilai minimum di D3 sebesar 39,633. Website 18 termasuk ke dalam cluster 1 yaitu cluster gambar karena memiliki nilai minimum di D1 sebesar 39,763. Website 19 termasuk ke dalam cluster 1 juga yaitu cluster gambar karena memiliki nilai minimum di D1 sebesar 35,137. Website 20 termasuk ke dalam cluster 3 yaitu cluster video karena memiliki nilai minimum di D3 sebesar 25,009.

\section{B. Hasil pengujian skenario 1}

Pada skenario 2 ini mengambil nilai centroid yang berbeda dengan skenario 1 seperti yang ditunjukkan pada Tabel 5.

TABLE V. TABEL CENTROID AWAL SKENARIO 2

\begin{tabular}{|l|r|r|r|}
\hline atribut & c1 & c2 & c3 \\
\hline akses gambar & 175 & 100 & 49 \\
\hline akses teks & 156 & 150 & 44 \\
\hline akses video & 179 & 169 & 102 \\
\hline
\end{tabular}

Nilai centroid pada cluster 1 akses gambar sebesar 175, sedangkan nilai centroid pada cluster 2 sebesar 100, dan nilai centroid pada cluster 3 sebesar 49. Nilai centroid pada cluster 1 akses teks sebesar 156, sedangkan nilai centroid pada cluster 2 sebesar 150, dan nilai centroid pada cluster 3 sebesar 44. Nilai centroid pada cluster 1 akses video sebesar 179, sedangkan nilai centroid pada cluster 2 sebesar 169, dan nilai centroid pada cluster 3 sebesar 102. Pada skenario 2 membutuhkan 11 kali iterasi sehingga menghasilkan clustercluster seperti yang ditunjukkan pada Tabel 6 . 
TABLE VI. TABel Pengetahuan

\begin{tabular}{|c|c|c|c|c|c|c|c|c|}
\hline nama website & akses gambar & akses text & o/vid & & D2 & D3 & MIN & CLUSTER \\
\hline website 1 & 156 & 150 & 44 & 70,52714 & 131,727 & 102,5967 & 70,52714 & $4 \mathrm{C} 1$ \\
\hline website 2 & 46 & 104 & 100 & 169,1954 & 0 & 87,89198 & & $0 \mathrm{C} 2$ \\
\hline website 3 & 179 & 169 & 102 & 86,83938 & 148,0473 & 145,7716 & 86,83938 & $8 \mathrm{C} 1$ \\
\hline website 4 & 75 & 50 & 50 & 143,943 & 79,1012 & 29,39078 & 29,39078 & $8 \mathrm{C} 3$ \\
\hline website 5 & 190 & 100 & 75 & 29,08312 & 146,2088 & 105,3229 & 29,08312 & $2 \mathrm{C} 1$ \\
\hline website 6 & 125 & 80 & 50 & 86,85953 & 96,52461 & 33,11413 & 33,11413 & $3 \mathrm{C} 3$ \\
\hline website 7 & 301 & 105 & 50 & 92,55311 & 259,8577 & 208,019 & 92,55311 & $1 \mathrm{C} 1$ \\
\hline website 8 & 99 & 70 & 30 & 116,8442 & 94,15413 & 10,04535 & 10,04535 & 5 C3 \\
\hline website 9 & 107 & 71 & 56 & 106,6985 & 82,13404 & 20,2507 & 20,2507 & $7 \mathrm{C3}$ \\
\hline website 10 & 175 & 100 & 49 & 33,93123 & 138,7732 & 85,63825 & 33,93123 & $3 \mathrm{C} 1$ \\
\hline website 11 & 90 & 80 & 19 & 125,5143 & 95,2523 & 25,29463 & 25,29463 & $3 \mathrm{C3}$ \\
\hline website 12 & 75 & 75 & 51 & 136,5735 & 63,89836 & 26,41969 & 26,41969 & $9 \mathrm{C3}$ \\
\hline website 13 & 100 & 65 & 37 & 116,3006 & 91,68424 & 3,942772 & 3,942772 & $2 \mathrm{C3}$ \\
\hline website 14 & 189 & 56 & 22 & 60,11304 & 169,8146 & 94,22507 & 60,11304 & $4 \mathrm{C} 1$ \\
\hline website 15 & 80 & 50 & 37 & 140,1903 & 89,67162 & 23,56037 & 23,56037 & $7 \mathrm{C3}$ \\
\hline website 16 & 87 & 60 & 40 & 129,777 & 84,95293 & 11,76281 & 11,76281 & $1 \mathrm{C} 3$ \\
\hline website 17 & 125 & 48 & 36 & 101,809 & 116,0733 & 33,65331 & 33,65331 & $1 \mathrm{C} 3$ \\
\hline website 18 & 203 & 75 & 31 & 36,54214 & 173,9281 & 106,7563 & 36,54214 & $4 \mathrm{C} 1$ \\
\hline website 19 & 275 & 75 & 50 & 72,50571 & 236,1821 & 178,638 & 72,50571 & $1 \mathrm{C} 1$ \\
\hline website 20 & 103 & 80 & 24 & 111,9289 & 97,98469 & 21,2902 & 21,2902 & $2 \mathrm{C3}$ \\
\hline
\end{tabular}

Hasil perhitungan ditunjukkan pada Tabel 6. Website 1 termasuk ke dalam cluster 1 yaitu cluster gambar berdasarkan nilai minimumnya adalah di D1 sebesar 70,527. Website 2 termasuk ke dalam cluster 2 berdasarkan nilai minimumnya berada di D2 sebesar 0. Website 3 termasuk ke dalam cluster 1 juga sama seperti website 1 karena website 3 memiliki nilai minimum yang berada di D1 sebesar 86,839. Website 4 termasuk ke dalam cluster 3 yaitu cluster video karena memiliki nilai minimum di D3 sebesar 29.390. Website 5 termasuk ke dalam cluster 1 yaitu cluster gambar karena memiliki nilai minimum di D1 sebesar 29.083. Website 6 termasuk ke dalam cluster 3 yaitu cluster video karena memiliki nilai minimum di D3 sebesar 33,114. Website 7 termasuk ke dalam cluster 1 yaitu cluster gambar karena memiliki nilai minimum di D1 sebesar 92,553. Website 8 termasuk ke dalam cluster 3 yaitu cluster video karena memiliki nilai minimum di D3 sebesar 10,045. Website 9 termasuk ke dalam cluster 3 juga yaitu cluster video karena memiliki nilai minimum di D3 sebesar 20,250. Website 10 termasuk ke dalam cluster 1 yaitu cluster gambar karena memiliki nilai minimum di D1 sebesar 33,931. Website 11 termasuk ke dalam cluster 3 yaitu cluster video karena memiliki nilai minimum di D3 sebesar 25,294. Website 12 termasuk ke dalam cluster 3 juga yaitu cluster video karena memiliki nilai minimum di D3 sebesar 26,419. Website 13 termasuk ke dalam cluster 3 yaitu cluster video karena memiliki nilai minimum di D3 sebesar 3,942. Website 14 termasuk ke dalam cluster 1 yaitu cluster gambar karena memiliki nilai minimum di D1 sebesar 60,113. Website 15 termasuk ke dalam cluster 3 yaitu cluster video karena memiliki nilai minimum di D3 sebesar 23,560. Website 16 termasuk ke dalam cluster 3 juga yaitu cluster video karena memiliki nilai minimum di D3 sebesar 11,762. Website 17 termasuk ke dalam cluster 3 yaitu cluster video karena memiliki nilai minimum di D3 sebesar 33,653. Website 18 termasuk ke dalam cluster 1 yaitu cluster gambar karena memiliki nilai minimum di D1 sebesar 36,542. Website 19 termasuk ke dalam cluster 1 juga yaitu cluster gambar karena memiliki nilai minimum di D1 sebesar 72,505. Website 20 termasuk ke dalam cluster 3 yaitu cluster video karena memiliki nilai minimum di D3 sebesar 21,290.

\section{SIMPULAN}

Dapat disimpulkan bahwa big data yang ada dalam log server web mengandung banyak informasi yang menghasilkan pengetahuan tentang cluster pengakses gambar/image, cluster pengakses teks, dan cluster pengakses audio/video. Pada pengujian skenario 1 menghasilkan dimana para pengguna web lebih senang mengakses gambar di web $7,14,18,19$. Sedangkan pada web $1,3,5,10$ para pengguna web lebih menyukai mengakses teks. Sedangkan pada web $2,4,6,8,9,11,12,13,15,16,17$,dan 20 para pengguna lebih suka menonton video-video. Hasil pengujian pada skenario 2 yaitu para pengguna web lebih senang mengakses gambar di web $1,3,5,7,10,14,18$ dan 19. Sedangkan pada web 2 para pengguna web lebih menyukai mengakses teks. Sedangkan pada web 4,6,8,9,11,12,13,15,16,17, dan 20 para pengguna lebih suka menonton video-video.

\section{PENGHARGAAN}

Ucapan terima kasih kepada lembaga LPPM Institut teknologi nasional Malang yang telah memberikan sponsor atau support terhadap berlangsungnya penelitian ini.

\section{REFERENSI}

[1] fadlan, C., S.Ningsih, \& A.P.Windarto.2018.Penerapan Metode Naive Bayes Dalam Klasifikasi kelayakan Keluarga Penerima Beras Rastra.JUTIM.Vol.3 No.1

[2] Bedboudi A.,C.Bouras, \& M.T.Kimour.2017.Indonesian Journal of Electrical Engineering and Informatics.Vol.5.No.3.ISSN:2089-3272, DOI: $10.1159 /$ ijeei.v5i3.299

[3] Ramdani, A.L, \& H.B.Firmansyah.2018.Clustering Application for UKT Determination using Pillar K-means clustering Algorithm and Flask Web Framework.Indonesian Journal of Electrical Engineering and Informatics.Vol.1.No.2.p-ISSN:2614-3372.e-ISSN:2614-6150

[4] Gustientiedina., M.H.Adiya, \& Y.Desnelita.2019.Penerapan Algoritma K-means untuk Clustering data Obat-Obatan Pada RSUD Pekanbaru.Jurnal nasional Teknologi dan Sistem Informasi.Vol.5.No.1p-ISSN : 2460-3465.e-ISSN : 2476-8812

[5] Darmansah, \& N.W.Wardani.2020.Analisa Penyebab Kerusakan Tanaman Cabai menggunakan Metode K-means.Jurnal Teknik Informatika dan Sistem Informasi.Vol.7.No.2.ISSN:2407-4322.eISSN:2503-2933

[6] Annur,H.2019.Penerapan Data mining menentukan Strategi Penjualan Variasi Mobil menggunakan Metode K-means Clustering.Jurnal Informatika UPGRIS.Vol.5.No.1.p/e ISSN: 2460-4801/2447-6645

[7] Handoko,K, \& L.S.Lesmana.2018.Pengelompokkan Data mining Pada Jumlah Penumpang Di Bandara Hang Nadim.CBIS Journal.Vol.6.No.2.p-ISSN: 2337-8794.e-ISSN: 2621-5292

[8] Arista,R.R.,R.A.Asmara, \&D.Puspitasari.2017.Pengelompokan Kejadian Gempa Bumi menggunakan Fuzzy C-Means Clustering. Jurnal teknologi Informasi dan Terapan.Vol.4No.2.ISSN: 235-838X

[9] Novianto,R., \& L.Geoirmanto. 2019.Penerapan data mining Menggunakan Algoritma K-means Clustering Untuk Menganalisa Bisnis Perusahaan Asuransi. Jurnal Teknik Informatika dan Sistem Informasi.Vo.6.No.1.ISSN: 2407-4322.e-ISSN: 2503-2933

[10] Han.J, M.Kamber,\& J.Pei.2012.Data mining Concepts and Techniques. Third edition.ISBN 978-0-12-381479-1

[11] Liu.B.Web data mining, Exploring Hyperlinks, Contents and Usage data", 2 nd edition, Springer New York, ISBN:9783642194597,2011 